\title{
The use of lip bumper to overcome lower lip sucking habit
}

\author{
Marcella Budhiawan, Krisnawati \\ Department of Orthodontics Faculty of Dentistry Universitas Indonesia
}

\begin{abstract}
The patient was an 16-year-old girl with a lower lip sucking habit with increased overjet, maxillary and mandibular generalized spacing. Hyperactivity of the mentalis muscle and deepening of the labiomental sulcus because of the abnormal sucking habit was observed. Orthodontic treatment was started with a lip bumper appliance to break the lower sucking habit and continued with fixed orthodontic mechanotherapy. The lip bumper appliance therapy resulted in the elimination of the lower lip sucking habit, musculus mentalis hyperactivity, and labiomental strain, and also overjet reduction. The use functional appliance in the treatment of malocclusions must be carefully selected according to the requirement of the case. It must be understood that the action of the mentalis muscle was the primary activator of the bumper.
\end{abstract}

Key words: Lip bumper, lip sucking habit.

\section{INTRODUCTION}

Dental position and stability are much affected by the balance of the surrounding muscles. The force of orbicularis oris and buccinator muscles is balanced by the opposing force from tongue. When there is a balance alteration in those muscles, like in lip sucking habit, lip biting, tongue thrusting, the morphology change in normal configuration of teeth and their supporting bones may cause malocclusion.

The manifestation of malocclusion varies, depending on the type, location, severity, frequency, and the habit period. The elimination of an abnormal habit is the basis of long term treatment and stability. In a patient with lip sucking or lip biting, lip bumper is a good treatment alternative in overcoming the bad habit and repairing malocclusion. ${ }^{1}$

Treatment of a female patient aged 16 years old having bad habit, sucking her lower lip, will be discussed. Treatment using lip bumper is aimed to resist hypertonicaty of the lower lip.

One of etiology factors malocclusion is abnormal habit of muscles which is commonly related to bone growth, teeth malposition, breathing disorder, speaking difficulty, unbalanced face muscles and psychological problems. Consequently, it is rather difficult to treat malocclusion without involving its reflex activity. ${ }^{2}$

Teeth are in a state of constant of dynamic balance. There are force balances between the muscles which are believed to influence the position and stability of dent alveolar complex. ${ }^{3}$ Graber $^{4}$ described this muscular system as buccinator mechanism. In this system, the forces to teeth are produced by the orbicularis oris, buccinator and superior pharyngeal constrictor muscles which are balanced by the opposing force from the tongue (Fig.1). 
Muscle balance around oral area can be disturbed if patients have bad habits such as thumb sucking, tongue thrusting, lip sucking, lip/nail biting, oral breathing, etc. ${ }^{5}$ In sucking or biting lower lip habit, there will be hypertonicity of mentalis muscle. These bad habits can be the main factor or the secondary one. When it becomes the main factor, there will be a big over jet with the upper anterior teeth tipping to labial and the lower anterior teeth tipping to lingual followed by light skeletal discrepancy. Lip sucking habit makes the normal over jet. ${ }^{4,6}$ Treatment with a functional larger appliance will succeed if such bad habits are the primary etiology factor. ${ }^{6}$

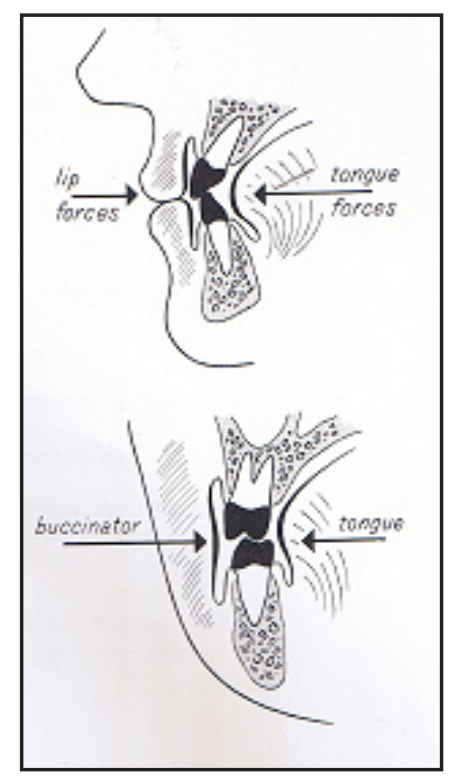

Figure 1. The balanced styles of lips, tongue and cheeks in teeth and their supporting bones structures, create the stable occlusion. ${ }^{4}$
The habit of sucking lip as a secondary factor usually occurs due to the sagittal discrepancy, like in mandibular retrognati. The upper incisive inclination can be normal and the space between upper and lower teeth occurs after the process of adaptation.

In lip sucking or lip biting, lip bumper is a proper treatment alternative to overcome the bad habit and malocclusion. ${ }^{1}$ Lip bumper is a simple functional appliance, removable, easily put on, and is well tolerated by patients. ${ }^{3}$ In orthodontics, lip bumper is used to increase the length and the width of teeth arches that can be used to overcome crowded teeth in a low to moderate degree, so it can reduce the need for extraction rotate molar,

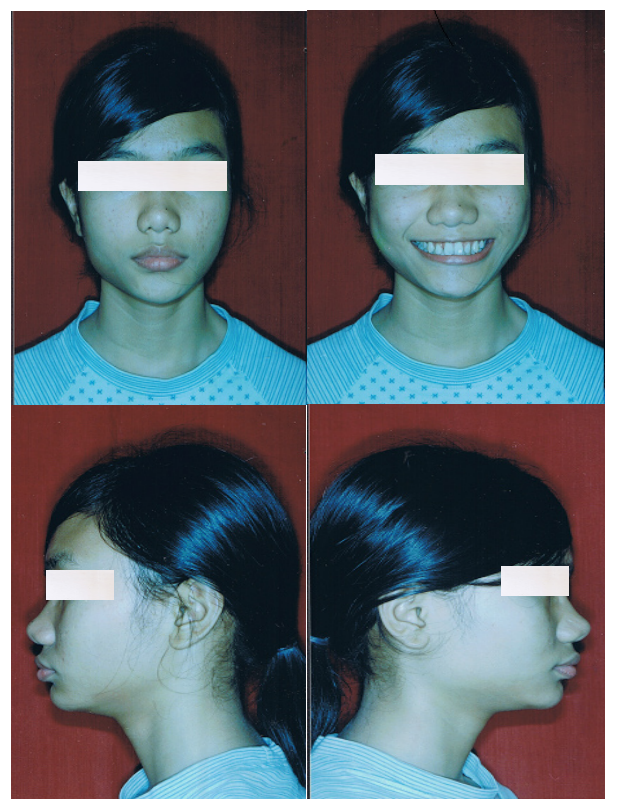

Figure 2. Extra oral photograph before treatment.
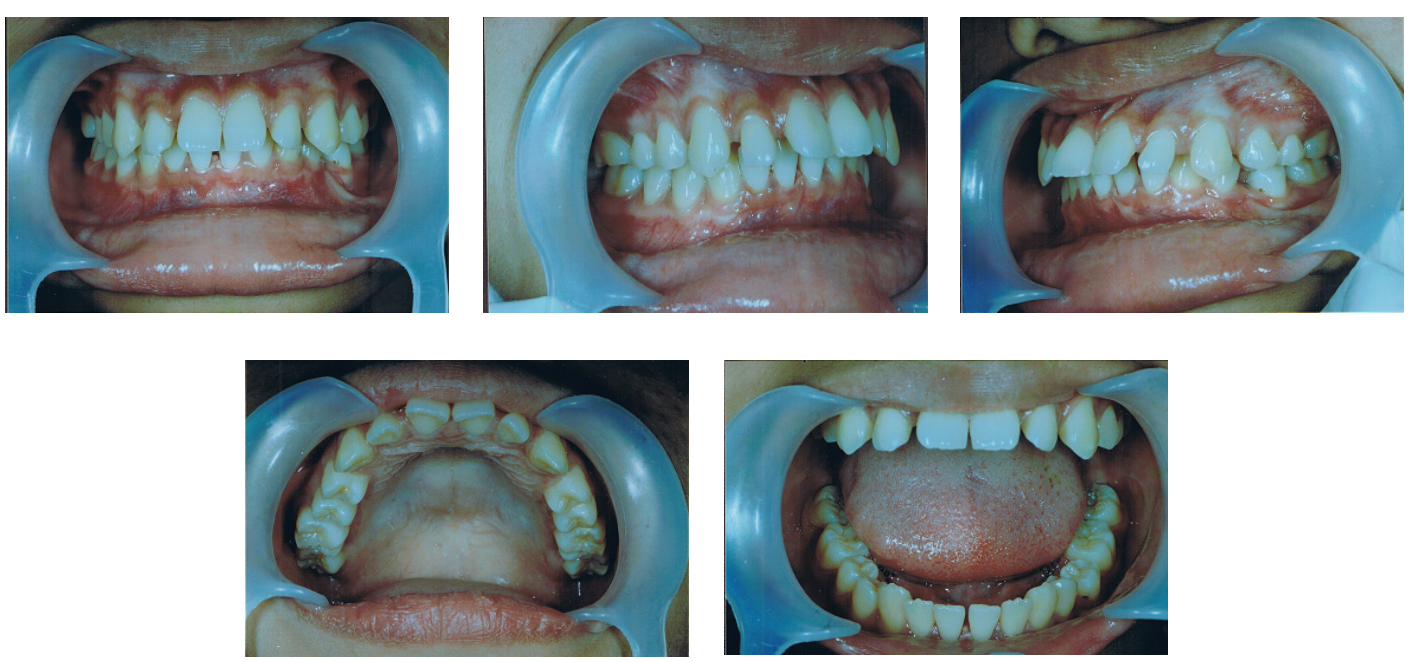

Figure 3. Intra oral photograph before treatment. 
maintain the first molar position and leeway space, control anchorage, reduce mentalis muscle hypertonicity, reduce over jet, and to eliminate the habit of biting or sucking of lower lip. 1,7-9

Lip bumper is made of stainless steel wire diameter 0.045 ". It is placed on the lower jaw from the right molar to the left molar. The curve of this lip bumper is located more to the gingival margin direction, $\pm 3 \mathrm{~mm}$ from the labial teeth surface. The anterior area can be covered by plastic or acrylic which functions to help the adaptation of lip and cheeks muscles, so the pressure of lip muscle on teeth will decrease. This appliance has a loop located in front of molar tube, and it is adjustable. ${ }^{10-11}$ Lip bumper is better used 24 hours within 6 to 18 months period, depending on teeth movement and the treatment goal. ${ }^{10}$ For uncooperative patients, elastic or ligature wire can be tied between lip bumper wire and hook on the molar band. ${ }^{9}$ The effect of using lip bumper is the forward movement of lower incisors and distal movement of molars. Those changes can happen because lip bumper holds lip muscles from lower teeth and let the force of tongue push lower teeth forward and laterally, so the length and the arch width of teeth increase. ${ }^{12-14}$

\section{CASE REPORT}

A sixteen year old female patient visited the Orthodontic RSGMP FKG UI Clinic with the complaint labioversion and diastema of anterior upper teeth. The extra oral check showed the patient has a mesofacial, symmetric, and balanced face with straight chin and convex profile (Fig. 2). The relation of the right molar was class II and the left molar class I. The relation of the right canines was class II and the left canines was class I. Patient had $9 \mathrm{~mm}$ anterior teeth over jet with $5 \mathrm{~mm}$ overbite (palatal bite). Deep curve of spee. Lower teeth midline shifted to the right $2 \mathrm{~mm}$ with an oval shape of the upper and lower jaw (Fig. 3).

The cephalometri analysis conclusion was orthognatic relation of the upper and lower jaw and convex profile bimaxillary dental protrusion. Patient had the tendency of horizontal face growth.

The treatment objectives were to eliminate the lip sucking habit, multiple diastema, protrusion, and palatal bite. Correct the deep curve of spee, coincide the upper and lower midline parallel with the face. Space excess would be corrected by posterior teeth mesial movement. The appliance used was a bumper and fixed appliance with standard bracket edgewise slot.022".

The treatment began in December 2006. In the lower jaw, double tube was used to place

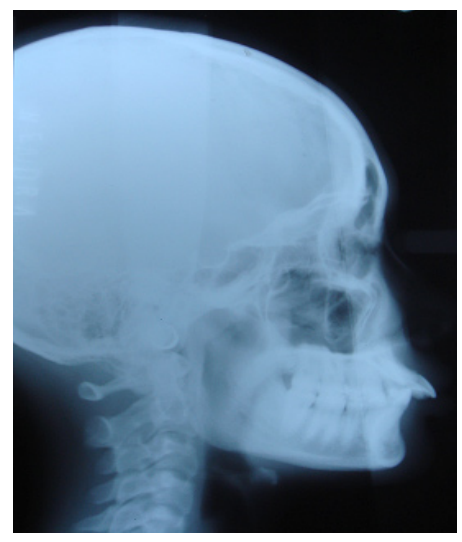

Figure 4. Cephalometric radiograph before treatment.

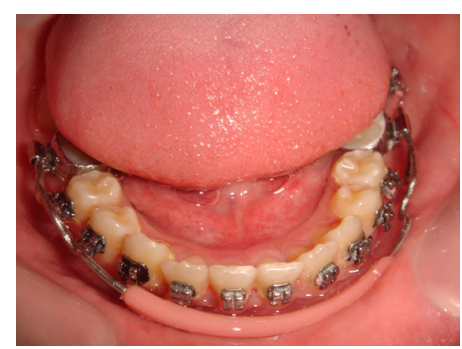

Figure 5. Lip bumper in the lower jaw.

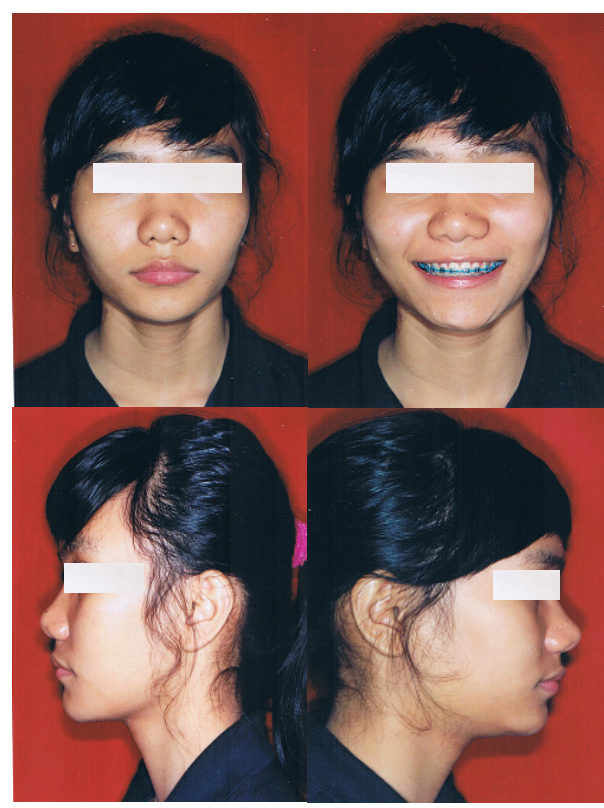

Figure 6. Extra oral photograph during treatment. 

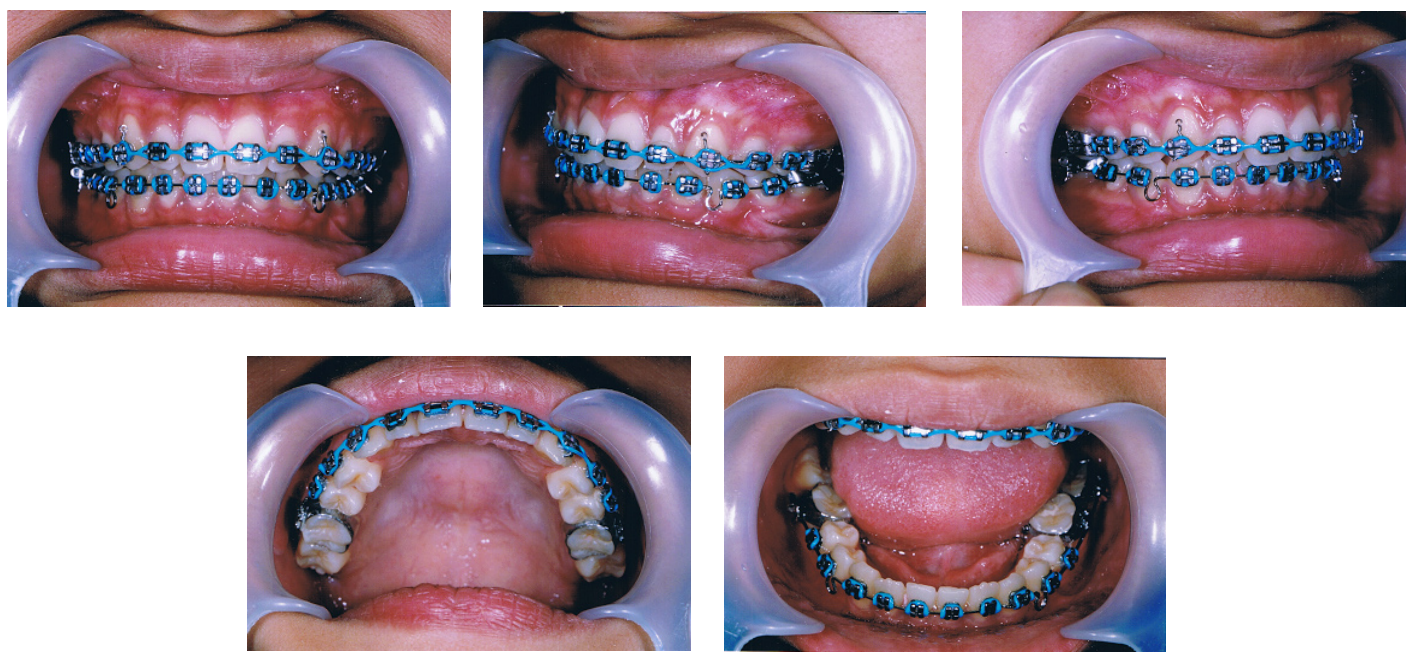

Figure 7. Intra oral photograph during treatment.

Table 1. Cephalometric values before and after treatment.

\begin{tabular}{lccc}
\hline & Mean & Before & After \\
\hline SNA & $82^{\circ}$ & $82^{\circ}$ & $82^{\circ}$ \\
SNB & $80^{\circ}$ & $79^{\circ}$ & $79^{\circ}$ \\
ANB & $2^{\circ}$ & $3^{\circ}$ & $3^{\circ}$ \\
The Wits & & $+2 \mathrm{~mm}$ & $+0.5 \mathrm{~mm}$ \\
Facial angle & $87^{\circ}$ & $88^{\circ}$ & $87^{\circ}$ \\
Angle of convexity & $0^{\circ}$ & $5^{\circ}$ & $6^{\circ}$ \\
Y-axis & $60^{\circ}$ & $58^{\circ}$ & $60^{\circ}$ \\
Go-angle & $123^{\circ}$ & $109^{\circ}$ & $109^{\circ}$ \\
SN-MP & $32^{\circ}$ & $23^{\circ}$ & $25^{\circ}$ \\
1 - T & $130^{\circ}$ & $96^{\circ}$ & $129^{\circ}$ \\
1 - SN & $104^{\circ}$ & $127^{\circ}$ & $101^{\circ}$ \\
1 - NA & $4 \mathrm{~mm}$ & $11 \mathrm{~mm}$ & $3 \mathrm{~mm}$ \\
1 - Apg & $4 \mathrm{~mm}$ & $13 \mathrm{~mm}$ & $5 \mathrm{~mm}$ \\
T - Apg & $2 \mathrm{~mm}$ & $2 \mathrm{~mm}$ & $2 \mathrm{~mm}$ \\
T - MP & $90^{\circ}$ & $114^{\circ}$ & $106^{\circ}$ \\
T - NB & $4 \mathrm{~mm}$ & $5 \mathrm{~mm}$ & $5 \mathrm{~mm}$ \\
Pg - NB & $4 \mathrm{~mm}$ & $2 \mathrm{~mm}$ & $2 \mathrm{~mm}$ \\
Upper lip-E line & $1 \mathrm{~mm}$ & $+1 \mathrm{~mm}$ & $0 \mathrm{~mm}$ \\
lower lip-E line & $0 \mathrm{~mm}$ & $+4 \mathrm{~mm}$ & $0 \mathrm{~mm}$ \\
S-Go:N-Me & $62-65 \%$ & $72.4 \%$ & $71.4 \%$ \\
\hline
\end{tabular}

the lip bumper. The lip bumper was installed permanently for 8 months using hook joint to the lip bumper wire and then it was ligated using ligature wire to the molar band.

The lip bumper was detached because the sulcus labiomentalis depth had decreased and the lower lip was no longer trapped between the upper and lower anterior teeth. The palatal bite and the deep curve of spee were corrected using the accentuated curve of spee in the upper jaw

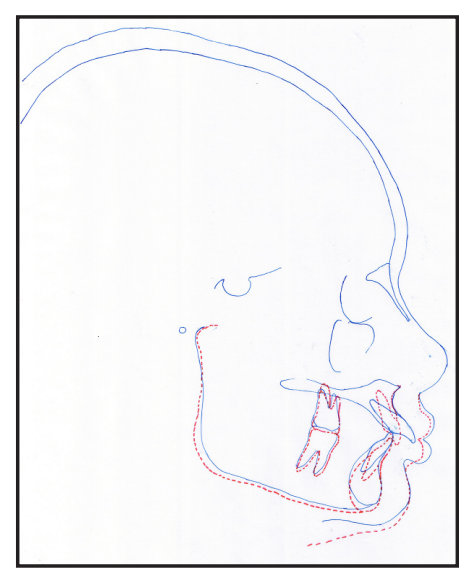

Figure 8. Cephalometric superimposed after 14 months treatment.

and the reversed curved spee in the lower jaw.

\section{DISCUSSION}

The patient had protrusive upper teeth. caused by the lower lip trapped between the upper and lower anterior teeth related to lower lip sucking habit. This habit was regarded as the primary factor, since there was a big over jet with the upper anterior teeth tipped to the labial. ${ }^{6}$

The use of lip bumper would reduce mental muscles hyperactivity so the upper anterior teeth retraction could be done in order to overcome the large over jet. The soft tissues around the teeth would adapt and they were expected to get their stability in their new positions. ${ }^{12}$ According to Houston ${ }^{15}$, the stability of the treatment result would be achievcd, if the position of lower lip covered $1 / 3$ upper incisive insisal. Overall, there 
was the over jet reduction, multiple diastema elimination, corrected palatal bite and deep curve of spee, and the patient's face profile correction.

\section{CONCLUSION}

The elimination of the bad habit is the basis of the treatment and long term stabilization. ${ }^{1}$ In this patient's case, lip bumper was chosen in order to overcome the bad habit of sucking the lower lip, so it was no longer trapped between the upper and lower anterior teeth. It is expected that after the treatment, there will be a normal occlusion and the long term stabilization of the treatment result will be obtained.

\section{REFERENCES}

1. Germec D, Taner TU. Lower lip sucking habit treated with a lip bumper appliance. Angle Orthod 2005;75(6):1071-6.

2. Moyers RE. Handbook of orthodontics. $4^{\text {th }}$ ed. Year Book, Medical Publisher; 1988. p. 152-6.

3. Soo ND, Moore RN. A technique for measurement of intraoral lip pressures with lip bumper therapy. Am J Orthod 1991;99:409-17.

4. Graber TM. Orthodontics: Principles and practice. $3^{\text {rd }}$ ed. Philadelphia: W.B Saunders Co.; 1972. p. 139-44,319-22.

5. Proffit WR, Fields HW, Ackerman JL. Contemporary orthodontics. $3^{\text {rd }}$ ed. St. Louis: Mosby Year Book Inc.; 2000. p. 120-4.
6. Graber TM, Rakosi T, Petrovic AG. Dentofacial orthopedics with functional appliance. St. Louis: Mosby; 1997. p. 154-5.

7. Osborn WS, Nanda RS, Curries GF. Mandibular arch perimeter changes with lip bumper treatment. Am J Orthod 1991;99:527-32

8. Solomon MJ, English JD, Magness WB, et al. Long-term stability of lip bumper therapy followed by fixed appliance. Angle Orthod 2006;76:36-42.

9. Bishara SE, Moin K. An evaluation of buccal shield treatment. Angle Orthod 2007;77(1):5763.

10. Viazis AD. Atlas of orthodontics: Principles and clinical applications. Philadelphia: W.B Saunders Co.; 1993;215-7.

11. Klocke A, Drmeddent, Nanda RS. Muscle activity with the mandibular lip bumper. Am J Orthod 2000;117:384-90.

12. Murphy CC, Magness WB, English JD. A longitudinal study of incremental expansion using a mandibular lip bumper. Angle Orthod 2003;73(4):396-400.

13. O’Donnell S, Nanda RS, Gosh J. Perioral forces and dental changes resulting from mandibular lip bumper treatment. Am J Orthod 1998;113(3):247-55.

14. Nevant CT, Buschang PH, Alexander RG. Lip bumper therapy for gaining arch length. Am J Orthod 1991;100:330-6.

15. Houston WJB. Walther's orthodontic notes. London: John Wright \& Sons Ltd.; 1983. p. 28,141 . 